\title{
Campimetry and visual changes after RHZE treatment for tuberculosis
}

\author{
Brunella Maria Pavan Taffner ${ }^{1 *} \mathbb{D}$, Luiz Guilherme Ito da Cruz , Flávio de Ávila Fowler', \\ Carolynne Cardoso Nawa' ${ }^{1}$, Marcia Telma Savioli², Denise Silva Rodrigues ${ }^{3}$, Octaviano Magalhães Junior ${ }^{1}$ and \\ Rubens Belfort Junior ${ }^{1,4}$
}

\begin{abstract}
Background: Tuberculosis (TB) caused by Mycobacterium tuberculosis has a high prevalence in Brazil (Global tuberculosis report 2020. Geneva: World Health Organization; 2020). The ethambutol-induced optic neuropathy damage is partly reversible, making its early diagnosis essential to reduce permanent visual damage.

Purpose: To observe alterations in the computerized campimetry, Ishihara test and visual acuity secondary to rifampicin, isoniazid, pyrimethamine, ethambutol (RHZE) treatment.

Methods: Patients undergoing treatment with RHZE at the tuberculosis service of the Federal University of São Paulo were recruited from March 2019 to December 2020. The best-corrected visual acuity (VA) measurements, Ishihara test and visual fields were performed at baseline, monthly, until 2 weeks after treatment.

Results: Twenty-five patients were included. The VA decreased significantly $(P=0.0129)$ post-treatment compared to month 1. The mean deviation (MD) did not decrease significantly $(P>0.05)$; the pattern standard deviation (PSD) decreased post-treatment compared to month $1(P=0.0371)$. Changes in the Ishihara test increased significantly $(P<0.0001)$ in the second month.
\end{abstract}

Conclusion: The VA and PSD decreased significantly after RHZE treatment. Changes in the Ishihara test were observed in the second month.

Trial registration: The Research Ethics Committee of Federal University of São Paulo, Paulista School of Medicine approved the study in March 2019. CAAE 04297018.4.0000.5505.

Keywords: Retina, Campimetry, Tuberculosis, Toxicity

\section{Introduction}

Tuberculosis (TB) caused by Mycobacterium tuberculosis has a high prevalence in Brazil [1]. Since 2009, the basic TB treatment in Brazil has included ethambutol in the regimen of rifampicin, isoniazid and pyrazinamide (RHZE) [2]. The adverse effects of ethambutol have been documented since its original use, with optic neuropathy

*Correspondence: brunellapavan@gmail.com

${ }^{1}$ Departament of Ophthalmology, Federal University of São Paulo,

UNIFESP, São Paulo, SP Botucatu, 822, Vila Clementino, Brazil

Full list of author information is available at the end of the article the most severe with an incidence of 22.5 cases $/ 1000$ patients [3].

The clinical characteristics of ethambutol-induced optic neuropathy are similar to those of compressive optic neuropathy with retrobulbar neuritis in a subacute clinical course consisting of decreased contrast sensitivity, painless loss of central vision, cecocentral scotomas, and dyschromatopsia. The neuropathic damage is partly reversible, making its early diagnosis essential to reduce permanent visual damage. original author(s) and the source, provide a link to the Creative Commons licence, and indicate if changes were made. The images or other third party material in this article are included in the article's Creative Commons licence, unless indicated otherwise in a credit line to the material. If material is not included in the article's Creative Commons licence and your intended use is not permitted by statutory regulation or exceeds the permitted use, you will need to obtain permission directly from the copyright holder. To view a copy of this licence, visit http://creativecommons.org/licenses/by/4.0/. The Creative Commons Public Domain Dedication waiver (http://creativeco mmons.org/publicdomain/zero/1.0/) applies to the data made available in this article, unless otherwise stated in a credit line to the data. 
The study goals were observation of changes the computerized campimetry, color test and visual acuity secondary to RHZE treatment.

\section{Methods}

Patients undergoing treatment for TB with RHZE were recruited from the TB service of the Federal University of São Paulo from March 2019 to December 2020. Only patients treated continuously with ethambutol were included in the study.

The Research Ethics Committee of Federal University of São Paulo, Paulista School of Medicine approved the study. All participants provided written informed consent in agreement with the Ethics Committee according to the recommendations of the Declaration of Helsinki.

All patients provided a medical history that included a description of their daily habits, past medical history, medication use, and history of color blindness. After clinical evaluation, the best-corrected visual acuity (VA) and Ishihara test was measured before treatment. Humphrey visual field analyzer central 24.2 (Carl Zeiss, Oberkochen, Germany) were performed after 2 weeks of treatment according to the guidelines of the infectious diseases department. The exams were performed monthly during six months of treatment. The last exam was realized 2 weeks after treatment.

With intention to mitigate the learning effect of the visual field test was compared the results from month 1 to month 2.

Patients were included who had no history of optic neuropathy such as glaucoma and optic neuritis; congenital dyschromatosis, such as color blindness and retinal diseases; significant opacity on slit-lamp or funduscopic examination; visual abnormalities or visual field defects; anterior-segment diseases except for dry eye syndrome; drug use that could induce ocular toxicity, except for ethambutol; or ocular or central nervous system TB. All patients were older than 18 years.

\section{Statistical analysis}

Data cleaning programs were developed to assess inconsistencies and prepare the database for further analysis. The data were analyzed using the STATA 14.0 program (StataCorp LP, College Station, TX).

Frequency tables were used for descriptive analysis. The normal distribution of the variables was assessed using the Shapiro-Wilk test. Clinical variables were compared between different time points using the Wilcoxon sign-ranked test. Associations between categorical variables were assessed using the chi-square test. Associations between outcomes and continuous variables were investigated using linear regression analysis. For all tests, $P<0.05$ was considered significant.
Table 1 Categorical variables of the sample

\begin{tabular}{lc}
\hline Parameter & No. (\%) \\
\hline Gender (\%) & $13(52)$ \\
Male & $12(48)$ \\
Female & \\
Ethnicity (\%) & $6(24)$ \\
White & $7(28)$ \\
Black & $12(48)$ \\
Mixed race & \\
Disease focus (\%) & $3(12)$ \\
Ganglionar & $5(20)$ \\
Pleural & $17(68)$ \\
Pulmonary & $25(100)$ \\
Total &
\end{tabular}

Table 2 Descriptive analysis of the sample

\begin{tabular}{lc}
\hline & Mean \pm SD (Median) \\
\hline Age (years) & $39.72 \pm 14.32(37.00)$ \\
Weight $(\mathrm{Kg})$ & $61.60 \pm 10.35(59.90)$ \\
Height $(\mathrm{M})$ & $1.68 \pm 0.06(1.70)$ \\
Dose $(\mathrm{Mg})$ & $18.72 \pm 1.65(18.36)$ \\
\hline
\end{tabular}

$\mathrm{SD}$, standard deviation

\section{Results}

Twenty-five patients were included in the study. Thirteen men and twelve women (mean age: 39.72 years; age's range: $25-54$ years), three patients were lost to follow-up (two in month 3 and one in month 2) and two died (liver cancer in month 2 and liver failure after month 3 of treatment). One patient cannot perform the visual field. All six patients eye exams were excluded. Six patients were white, seven black and twelve mixed race. Three patients presented with ganglionar TB, five pleural, and seventeen pulmonary disease focus (Table 1).

The mean patient weight was $61.60 \mathrm{~kg}$ and height $1.68 \mathrm{~m}$ (Table 2).

Fifteen patients $(60 \%)$ were formally actively employed, four $(16 \%)$ unemployed, three $(12 \%)$ were students, two (8\%) were retired, and one (4\%) was a housewife.

Seventeen (68\%) patients had no comorbidities, two (8\%) had primary arterial hypertension isolated, two $(8 \%)$ pulmonary fibrosis, one (4\%) was positive for human immunodeficiency virus (HIV), one (4\%) had asthma, one (4\%) had rheumatoid arthritis and primary arterial hypertension, one (4\%) had hypothyroidism.

Two (8\%) patients reported using marijuana and cocaine. 
Table 3 Comparison of results at months 1 and 2 of treatment

\begin{tabular}{lccr}
\hline Parameter & $\begin{array}{l}\text { First month } \\
\text { Mean } \pm \text { SD(median) }\end{array}$ & $\begin{array}{l}\text { Second month } \\
\text { Mean } \pm \text { SD(median) }\end{array}$ & \\
\hline Visual acuity & $0.04 \pm 0.07(0.00)$ & $0.05 \pm 0.11(0.00)$ & 0.7472 \\
Ishihara & $0.23 \pm 0.74(0.00)$ & $0.82 \pm 1.17(0.00)$ & $<\mathbf{0 . 0 0 0 1}$ \\
VF MD & $-1.81 \pm 2.48(-1.27)$ & $-2.14 \pm 3.41(-1.24)$ & 0.9860 \\
VF PSD & $2.65 \pm 2.11(2.09)$ & $2.78 \pm 2.15(2.10)$ & 1.0000
\end{tabular}

$\mathrm{SD}$, standard deviation; VF MD, visual field mean deviation; VF PSD, visual field pattern standard deviation

Table 4 Comparison of results at baseline and post-treatment

\begin{tabular}{lccc}
\hline Parameter & $\begin{array}{l}\text { Baseline } \\
\text { Mean } \pm \text { SD(median) }\end{array}$ & $\begin{array}{l}\text { Post- Treatment } \\
\text { Mean } \pm \text { SD(median) }\end{array}$ & PValue \\
\hline Visual acuity & $0.04 \pm 0.06(0.00)$ & $0.08 \pm 0.17(0.00)$ & $\mathbf{0 . 0 1 2 9}$ \\
Ishihara & $0.41 \pm 0.92(0.00)$ & $0.76 \pm 1.18(0.00)$ & 0.1121 \\
VF MD & $-1.84 \pm 2.75(-1.22)$ & $-2.19 \pm 5.19(-0.49)$ & 0.8575 \\
VF PSD & $2.77 \pm 2.38(2.09)$ & $2.44 \pm 1.88(1.76)$ & $\mathbf{0 . 0 3 7 8}$ \\
\hline
\end{tabular}

$\mathrm{SD}$, standard deviation; VF MD, visual field mean deviation; VF PSD, visual field pattern standard deviation

Fourteen (56\%) patients were from the state of São Paulo, eight (32\%) from northeastern Brazil, two (8\%) from the other southeastern states, and one (4\%) from southern Brazil.

The final sample consider for exams was 19 patients, 38 eyes.
Changes in the Ishihara test increased significantly $(P<0.0001)$ in the second month. About the Ishihara test, was considered the numbers of plates read correctly. The $\mathrm{VA}$, the mean deviation (MD) and the pattern standard deviation (PSD) did not change significantly between months 1 and 2 (Table 3 ).

The VA decreased significantly $(P=0.0129) 2$ weeks after treatment compared to baseline. The mean deviation did not change significantly $(\mathrm{P}>0.05)$; however, the PSD decreased after treatment compared to baseline $(P=0.0371)$ (Table 4).

All 38 eyes included in the visual field analysis had no significant scotomas (considered more than one point $<0.5 \%$ at pattern deviation; reduced MD or PSD) at baseline ( 2 weeks of treatment). The Humphrey visual field analysis showed scotoma in ten eyes $(26 \%)$ central; seven eyes (18\%) upper arched; seven eyes (18\%) upper nasal peripheral; two eyes (5\%) central and upper arched; two eyes $(5 \%)$ upper temporal peripheral; two eyes $(5 \%)$ lower temporal peripheral; eight eyes (21\%) no scotoma after RHZE treatment (Table 5).

\section{Discussion}

In 2009, the World Health Organization Guideline recommended adding ethambutol throughout the standardized treatment of new cases of active TB in populations with an increased prevalence of resistance to isoniazid, with the goal of reducing the risk of creating strains

Table 5 Humphrey visual field analysis 24.2 after treatment

\begin{tabular}{|c|c|c|}
\hline Patient & Right eye & Left eye \\
\hline 1 & Central scotoma & Central scotoma \\
\hline 2 & Upper arched scotoma & Upper arched scotoma \\
\hline 3 & No scotoma & No scotoma \\
\hline 4 & No scotoma & Central scotoma \\
\hline 5 & Central scotoma & Central scotoma and upper arched scotoma \\
\hline 6 & No scotoma & No scotoma \\
\hline 7 & Upper nasal peripheral scotoma & Upper temporal peripheral scotoma \\
\hline 8 & Central scotoma & Central scotoma \\
\hline 9 & Upper nasal peripheral scotoma & Lower temporal peripheral scotoma \\
\hline 10 & Upper nasal peripheral scotoma & No scotoma \\
\hline 11 & Central scotoma & Upper nasal peripheral scotoma \\
\hline 12 & No scotoma & Central scotoma \\
\hline 13 & Central scotoma & Central scotoma \\
\hline 14 & Upper arched scotoma & Upper arched scotoma \\
\hline 15 & Upper arched scotoma & Central scotoma and upper arched scotoma \\
\hline 16 & No scotoma & Lower temporal peripheral scotoma \\
\hline 17 & Upper arched scotoma & Upper nasal peripheral scotoma \\
\hline 18 & Upper temporal peripheral scotoma & Upper nasal peripheral scotoma \\
\hline 19 & Upper nasal peripheral scotoma & Upper arched scotoma \\
\hline
\end{tabular}


resistant to multiple drugs. The Brazilian population is included in this at-risk population [4].

The basic TB treatment regimen in Brazil for new cases of pulmonary or extrapulmonary $\mathrm{TB}$ with or without HIV and patients over 10 years of age is a combination of fixed-dose tablets of $150 \mathrm{mg}$ of rifampicin, $75 \mathrm{mg}$ of isoniazid, $400 \mathrm{mg}$ of pyrazinamide, and $275 \mathrm{mg}$ of ethambutol for two months and after $150 \mathrm{mg}$ of rifampicin, $75 \mathrm{mg}$ of isoniazid for four months. For children under 10 years of age, the combination of rifampicin, isoniazid, and pyrazinamide remains. The number of tablets administered daily is based on the patient's weight range, i.e., between 20 and $35 \mathrm{~kg}$ two tablets/day, between 36 and $50 \mathrm{~kg}$ three pills/day, and over $50 \mathrm{~kg}$ four pills/day [2, 4].

Central scotoma is the most common visual field defect [5], the same as our research showed, but bitemporal defects [6] and peripheral field constriction have also been described [7].

The current research showed PSD decreased after treatment compared to first month, therefore campimetry can be a screening test. Considering the learning effect, MD and PSD did not change significantly between months 1 and 2.

Dyschromatopsia is reported as the first symptom of toxic optic neuropathy. Garg et al. observed color vision abnormalities $12.6 \%$ of the eyes of 64 patients studied [8]. Some researchers have related a red-green dyschromatopsia, but others have found a predominantly blue-yellow one [9]. Changes in the Ishihara test were observed in the second month of treatment with RHZE, with improvement at post treatment in our study.

Ishihara test is considered the gold standard for the identification of congenital deficiencies for color vision, mainling for the red-green color abnormalities, but it can also be used for acquired deficiencies [10-12]. Because, an expressive percentage of the population has some degree of color vision alteration, the congenital dyschromatosis and changes in the baseline Ishihara test were considered exclusion factors. The Ishihara test was used due to its ease of application, thinking in a primary care context.

Patients treated with ethambutol $25 \mathrm{mg} / \mathrm{kg} /$ day had a $5 \%$ to $6 \%$ incidence of optic neuropathy; patients receiving doses of $15 \mathrm{mg} / \mathrm{kg} /$ day had less than a $1 \%$ incidence $[13,14]$. The current study the mean dose was $18.72 \mathrm{mg} /$ $\mathrm{kg} /$ day. The basic TB treatment regimen in Brazil is a combination of fixed-dose tablets, at certain weight ranges, what determines that some patients receive a higher dose per kilogram than others.

Symptoms usually develop between 4 and 12 months of ethambutol use, but they also can develop, although rarely, after a few days of starting therapy [15]. We observed VA decreases after 6 months of treatment. The fundoscopy findings typically are normal, especially in the early stages of the disease. Therefore, studies evaluating the risk factors for development of optic neuropathy due to the use of ethambutol and development of tests to identify the signs of this neuropathy early are important and necessary for clinical practice.

A limitation of this study was the inability to evaluate the use of ethambutol alone.

\section{Conclusion}

The VA and PSD decreased significantly after RHZE treatment. Changes in the Ishihara test were observed in the second month of treatment.

\section{Abbreviations}

MD: Mean deviation; PSD: Pattern standard deviation; RHZE: Rifampicin, isoniazid, pyrimethamine, ethambutol; TB: Tuberculosis; VA: Visual acuity.

\section{Acknowledgements}

Not applicable.

\section{Authors' contributions}

BMPT, LGIT, FAF, CCN, MTGS, DSR performed the examination. BMPT analyzed, interpreted the patient data and wrote de manuscript. OMJ and RBJ participated in the study design and reviewed de manuscript. All authors read and approved the final manuscript.

\section{Funding}

The authors declare that they have no funding for the study.

Availability of data and materials

The datasets used and/or analysed during the current study are available from the corresponding author.

\section{Declarations}

\section{Ethics approval and consent to participate}

The Research Ethics Committee of Federal University of São Paulo, Paulista School of Medicine approved the study in March 2019. CAAE 04297018.4.0000.5505.

\section{Consent for publication}

All participants provided written informed consent in agreement with the Ethics Committee according to the recommendations of the Declaration of Helsinki.

\section{Competing interests}

The authors declare that they have no competing interests.

\section{Author details}

${ }^{1}$ Departament of Ophthalmology, Federal University of São Paulo, UNIFESP, São Paulo, SP Botucatu, 822, Vila Clementino, Brazil. Departament of Pneumology, Federal University of São Paulo, UNIFESP, São Paulo, Brazil. ${ }^{3}$ Departament of Infectology, Instituto Clemente Ferreira, São Paulo, Brazil. ${ }^{4}$ Research Department, Instituto de Visão, IPEPO, São Paulo, Brazil.

Received: 4 November 2021 Accepted: 20 February 2022 Published online: 07 March 2022

References

1. World Health Organization. Global tuberculosis report 2020. Geneva: World Health Organization; 2020. 
2. Manual de Recomendações para o Controle da Tuberculose no Brasil/ Ministério da Saúde, Secretaria de Vigilância em Saúde, Departamento de Vigilância das Doenças Transmissíveis. Brasília, Ministério da Saúde. 2019.

3. Ezer N, Benedetti A, Darvish-Zargar M, Menzies D. Incidence of ethambutol-related visual impairment during treatment of active tuberculosis. Int J Tubercu Lung Dis. 2013;17:447-55.

4. World Health Organization. Treatment of tuberculosis: guidelines. 4th ed. Geneva: World Health Organization; 2009.

5. Melamud A, Kosmorsky GS, Lee MS. Ocular ethambutol toxicity. Mayo Clin Proc. 2003;78:1409-11.

6. Boulanger Scemama E, Touitou V, Le Hoang P. Bitemporal hemianopia as presenting sign of severe ethambutol toxicity. J Fr Ophtalmol. 2013;36:e163-7.

7. Kwok A. Ocular toxicity of ethambutol. Hong Kong Med Diary. 2006;11:27-9.

8. Garg P, Garg R, Prasad R, Misra AK. A prospective study of ocular toxicity in patients receiving ethambutol as a part of directly observed treatment strategy therapy. Lung India. 2015;32:16-9.

9. Polak BC, Leys M, van Lith GH. Blue-yellow colour vision changes as early symptoms of ethambutol oculotoxicity. Ophthalmologica. 1985;191(4):223-6.

10. Birch J. Efficiency of the Ishihara test for identifying red-green colour deficiency. Ophthalmic Physiol Opt. 1997;17(5):403-8.

11. Crone RA. Quantitative diagnosis of defective colour vision. A comparative evaluation of the Ishihara test, the Farnsworth Dichotomous test and the H-R-R polychromatic plates. Am J Ophthalmol. 1961;51:298-305.

12. Hardy $L H$, Rand G, Rittler MC. Tests for deteccion of colour blindness. An evaluation of the Ishihara test. AMA Arch Ophthalmol. 1945;3534:295-302.

13. Sivakumaran P, Harrison AC, Marschner J, et al. Ocular toxicity from ethambutol: a review of four cases and recommended precautions. N Z Med J. 1998;111:428-30.

14. Petri WA Jr. Drugs used in the chemotherapy of tuberculosis, Mycobacterium avium complex disease, and leprosy. In: Hardman JS, Limbird LE, editors. Goodman \& Gilman's the pharmacological basis of therapeutics. 10th ed. New York: McGraw-Hill; 2001. p. 1279-80.

15. Fox SH. Rapid-onset reversible ocular toxicity from ethambutol therapy. Am J Med. 1991;90:404-6.

\section{Publisher's Note}

Springer Nature remains neutral with regard to jurisdictional claims in published maps and institutional affiliations.

Ready to submit your research? Choose BMC and benefit from:

- fast, convenient online submission

- thorough peer review by experienced researchers in your field

- rapid publication on acceptance

- support for research data, including large and complex data types

- gold Open Access which fosters wider collaboration and increased citations

- maximum visibility for your research: over 100M website views per year

At BMC, research is always in progress.

Learn more biomedcentral.com/submissions 